\title{
Production and Characterization of Biodiesel Fuel Derived from Neem (Azadirachta Indica) Seed using Two Cylinder Diesel Engine Model
}

\author{
D. Y. Dasin'1, I. Yahuza² \\ ${ }^{1}$ Associate Professor, ${ }^{2}$ Senior Lecturer \\ 1Department of Mechanical Engineering, Modibbo Adama University of Technology Yola, Nigeria \\ 2Department of Mechanical/Production Engineering, Nigerian Army University, Biu, Borno, Nigeria
}

\begin{abstract}
How to cite this paper: D. Y. Dasin | I. Yahuza "Production and Characterization of Biodiesel Fuel Derived from Neem (Azadirachta Indica) Seed using Two Cylinder Diesel Engine Model" Published in International Journal of Trend in Scientific Research and Development (ijtsrd), ISSN: 24566470, Volume-3 | Issue-4, June 2019, pp.761-766, URL: https://www.ijtsrd.c om/papers/ijtsrd23 903.pdf

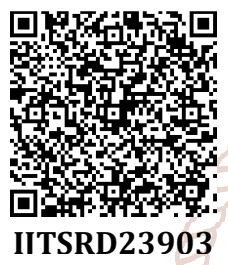

Copyright (c) 2019 by author(s) and International Journal of Trend in Scientific Research and Development Journal. This is an Open Access article distributed under the terms of the Creative Commons

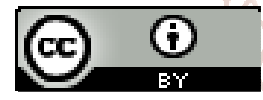
Attribution License (CC BY 4.0) (http://creativecommons.org/licenses/ by $/ 4.0$ )

been helping the world to meet its energy demand. These fuels are depleting and the world population is increasing every day. The tremendous increase in the production of automotive and other related product results in greater demand for such energy source. As a result, there are challenges in the price and supply of fossil fuels. Also the emission produce by the combustion of fossil fuels contributes to air pollution and global warming. Hence, renewable and clean alternative fuels have received increasing attention for current and future utilization.

Biodiesel as one of the alternatives to fossil fuel for diesel engines has become increasingly important due to environmental consequences of petroleum - fueled diesel engines and the decreasing petroleum resources. Biodiesel is a vegetable oil or animal fat-based diesel fuel consisting of long chain alkyl (methyl, ethyl or propyl) esters [1].

Biodiesel can be produced from natural oil which is renewable resources and animal fats. Vegetable oils have become more attractive owing to its environmental benefits and the fact that it is produced from renewable sources, it is biodegradable and non-toxic. Another advantage using vegetable oils for biodiesel production is that it has high energy content compared to conventional diesel; vegetable oils have $90 \%$ energy content of diesel. Vegetable oils are extracted from edible and non-edible, renewable oilseeds such as groundnut, neem seeds, soybean, jatropha seeds, rapeseeds, cotton seeds etc. but the use of non-edible seeds tends to be more cost efficient and economical [2].

Neem seeds are non-edible and very good sources of vegetable oils. Biodiesel can be produced from neem seeds vegetable oils using transesterification process, which is the reaction of the neem seeds oil with alcohol (Methanol) to form Neem Oil Methyl Ester (NOME) and glycerol as byproduct. Neem Oil Methyl Ester (NOME) is the chemical term for the biodiesel [3].

Neem (Azadirachta Indica) is a tree of the mahogany family, melieae which is abundantly grown in various parts of Asia and Africa. Neem grows on almost all types of soil. It is typically grown in tropical and Semitropical regions. The neem tree popularly referred in Hausa as DogonYaro, is 
characterized by it broad dark brown stem and widely spread branches. It is a fast growing plant with long productive life span of 150 to 200 years, its ability to survive on drought and poor soils at a very hot temperature of $44{ }^{\circ} \mathrm{C}$ and a low temperature of up to $4^{\circ} \mathrm{C}$ as well as its high oil content of 30.7 to $60 \%$. A mature Neem tree produces 30 to $50 \mathrm{~kg}$ fruit every year [4].

The Neem seed fruit is a smooth, olive-like drupe which varies in shape from elongate oval to nearly roundish, and when ripe is $1.4-2.8$ centimeters by $1.0-1.5$ centimeters. The fruit skin (exocarp) is thin and the bitter-sweet pulp (mesocarp) is yellowish-white and very fibrous. The mesocarp is 0.3 - 0.5 centimeters thick. The white, hard inner shell (endocarp) of the fruit encloses one rarely two, or three, elongated seeds (kernels) having a brown seed coat. Neem fruit is green in color initially and gradually turns to yellow when fully ripened. A matured fruit is very fleshy and filled with sweetish fluid. Fruit contains 40 - 55\% water content [5].

Neem oil is a vegetable oil pressed from the seeds of neem. The oil varies in colour, ranging from yellowish brown to dark brown, it has a strong odour that is said to combine the odours of peanut and garlic, it is bitter in taste due to presence of triglyceride and triterpenoid in its constituents. Neem oil also contains steroids (Campestral, Beta-sisterol, stigma sterol) and a plethora of triterpenoids of which azadirachtin is most widely studied. The percentage of the oil in the seed makes it a good resource and has high potential for production of biodiesel. Neem oil will become a good potential supplier of biodiesel in future. The biodiesel is a mono alkyl ester (Methyl Ester) of long chain fatty acid derived from renewable lipids of neem oil [6].

The Experimental analysis of the engine with various types of biodiesel and their blends conducted by [7] shows that much time and effort is required. In the present investigation, biodiesel is produced using unrefined neem seed oil. The performance tests are simulated in model of two cylinder diesel engine using biodiesel blend and petro-diesel as fuel. The effects of relative air-fuel ratio and compression ratio on the engine performance for different fuels are also analyzed using this model. The performances were compared with that of pure diesel fuel and observed.

\section{MATERIALS AND METHODS}

\section{$2.1 \quad$ Materials and Equipment}

Materials used are: Neem seeds, Petroleum diesel, Methanol, N-Hexane, Reagent water, Acetic Acid, Hydrochloric acid, Chloroform, Iodine Solution, Phenolphthalein Indicator, Sodium hydroxide $(\mathrm{NaOH})$, Potassium iodine solution, and Sodium thiosulfate solution.

Equipment used are: Metal hammer, Digital balance, Magnetic stirrer, Soxhlet extractor and accessories, Reflux condenser, Thermometer, Heating mantle, Stirrer, Reagent bottle, Stop watch, Hydrometer, Separating funnel, Conical flask, Volumetric flask, Desiccators, Beaker, Oven, Mantle and pestle.

\subsection{Methods}

The methods used in carrying out this research are:

1. Collection and Preparation of seeds

2. Oil extraction

3. Biodiesel production

4. Modeling and simulation of fuel characteristics

\subsubsection{Collection and preparation of seeds}

Ten kilogram (10 kg) of Neem seeds were collected from available sources within and outside Abubakar Tafawa Balewa University Bauchi Metropolis, the seeds was dried under room temperature to reduce moisture content and increase oil yield. The seed were taken to the chemistry laboratory, faculty of science, Abubakar Tafawa Balewa University Bauchi for oil extraction.

\subsubsection{Oil extraction}

The process of extraction of vegetable oil involves the removal of oil from plant, components, typically seeds. This can be done via mechanical extraction using an oil mill, traditional extraction using manual pressing or chemical extraction using solvent. The processing of vegetable oil in commercial applications is commonly done by chemical extraction, using solvent extracts, which produces higher yields, fast and less expensive. The most common solvent is petroleum-derived hexane.

In the method mentioned above, a soxhlet extraction which is a laboratory apparatus designed for the extraction of lipids from solid materials is used. A soxhlet Extractor has three main sections: a percolator (boiler and reflux) which circulates the solvents, a thimble (usually made of thick filter paper (which retains the solid to be laved, and a siphon mechanism, which periodically empties the thimble.

\section{Procedure}

$250 \mathrm{ml}$ clean boiling flask was dried in an oven at $105-110{ }^{\circ} \mathrm{C}$ for about 30 minutes. This was then transferred into a desiccator and allowed to cool; a weighed amount of the sample (grounded seeds) was carefully poured into a labeled thimble. The boiling flask was filled with about $300 \mathrm{ml}$ of nHexane. The extraction thimble was plugged lightly with cotton wool. The soxhlet apparatus was assembled and refluxing was carried out for about 6 hours. The thimble was carefully removed and the $n$ - hexane in the top container of the set up was drained into another container for re use. When the flask was almost free of n-hexane, it was removed and dried at $105{ }^{\circ} \mathrm{C}-110^{\circ} \mathrm{C}$ for an hour. It was transferred from the oven into a desiccator and allowed to cool then weighed. The oil obtained, was therefore stored in hermetically closed bottle.

\subsubsection{Biodiesel production}

This is the next stage after oil has been produced. Biodiesel production is the process of producing the biofuel, biodiesel, through the chemical reactions of transesterification and esterification.

A measuring cylinder was used to measure $40 \mathrm{ml}$ of methanol and transferred to a $250 \mathrm{ml}$ beaker. An electric balanced was used to measure $1 \mathrm{~g}$ of potassium hydroxide. The potassium hydroxide was slowly added to the methanol. The mixture was gently stirred using a glass rod until the potassium hydroxide completely dissolved in the methanol.

$200 \mathrm{ml}$ of the extracted oil was measured and transferred into a $500 \mathrm{ml}$ beaker. The potassium methoxide solution prepared was added to the oil. The residual was heated and mixed well using magnetic stirrer. The mixture was transferred to separating funnel and left for 24 hours to settle. The lighter color layer of biodiesel was observed on the surface and a darker colored layer of glycerol was observed in the separating funnel. 


\subsubsection{Modeling}

In building a GT-POWER model the first step is to import the necessary templates from the Template Library. The template library contains all of the available templates that can be used in GT-POWER. Some of these templates are copied into the project before they can be used to create objects and parts.

The following engine parameters were modeled using GT power model suite and all procedures duly followed to obtain optimum results.

\section{i. Cylinder}

The Engine Cylinder is somewhat unique, because the majority of the input to the object comes in the form of reference objects, which define sub-models for the cylinder such as geometry, wall temperature, heat transfer, in-cylinder flow and combustion.

\section{ii. Cylinder initial state object}

The cylinder initial state can be the same as the initial state of the intake runner and intake port.

\section{iii. Cylinder heat transfer object}

This object is used to describe the in-cylinder heat transfer characteristics between the gas and the combustion chamber walls. The Woschni heat transfer model is use because it is the industry standard, easy to use and gives good estimates of in-cylinder heat transfer.

iv. Head/bore area ratio and piston/bore area ratio The Head/Bore Area Ratio compares the surface area of the head to the bore area. The Piston/Bore Area Ratio compares the surface area of the piston to the bore area. This is a simple way of accounting for heat transfer from a concave head, flat piston combination in an SI application, and a flat head, bowl piston combination in a DICI application, without explicitly defining the detailed geometry.

Another attribute is the radiation multiplier. For SI engines radiation is typically not a factor, and so the recommended value is ign (ignore), which equals 0 , meaning radiation will not be included in the heat transfer analysis. Conversely, for diesel engines radiation is important because the soot particles actually radiate. Therefore, the recommended value for diesel engines is 1 .

\section{v. Engine crank train}

This object defines the engine type, cylinder arrangement, firing order, and other engine block and crankshaft characteristics.

\subsubsection{Run setup/case setup/plot setup}

Once the model is fully built, information such as case specific input, type of simulation, and desired output must be described. Most of this is accomplished through selections under the Run menu.

\section{i. Run setup}

Procedure:

Select Run $\rightarrow$ Run Setup. There are many folders inside Run Setup and several of the folders have values that are required in order to run the model. Fill in the following values in the TimeControl, Initialization, FlowControl, and ThermalControl folders as shown in figures 1 and 2 .

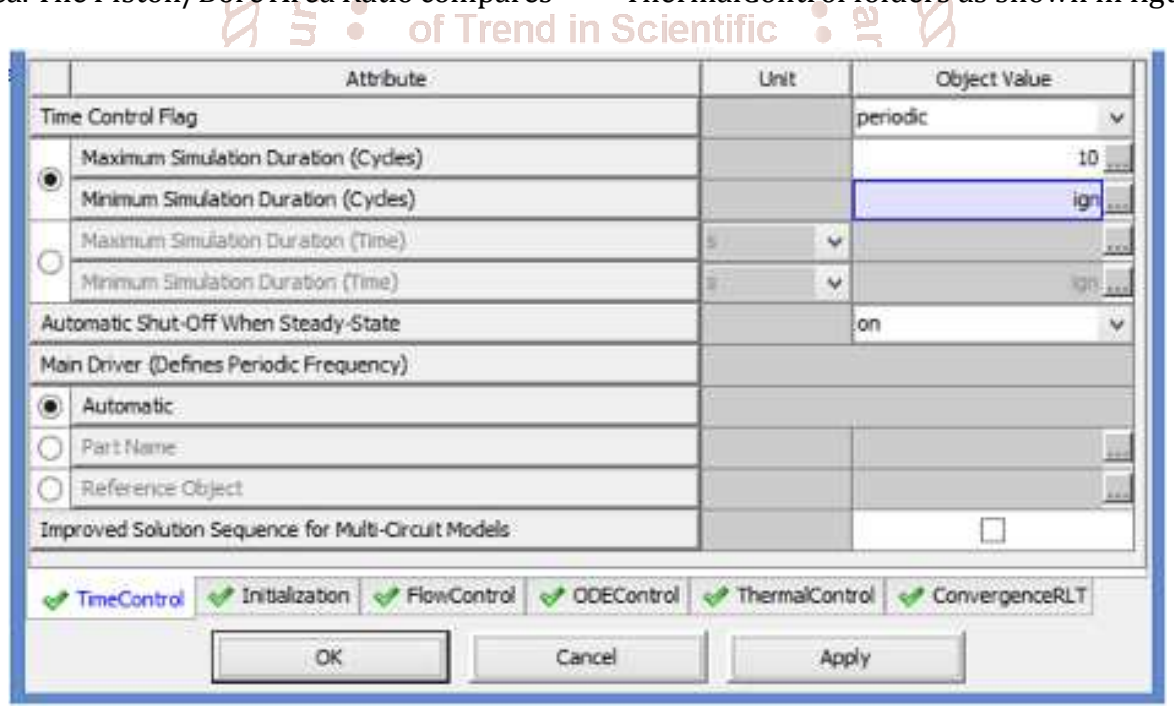

Figure 1; Time control folder

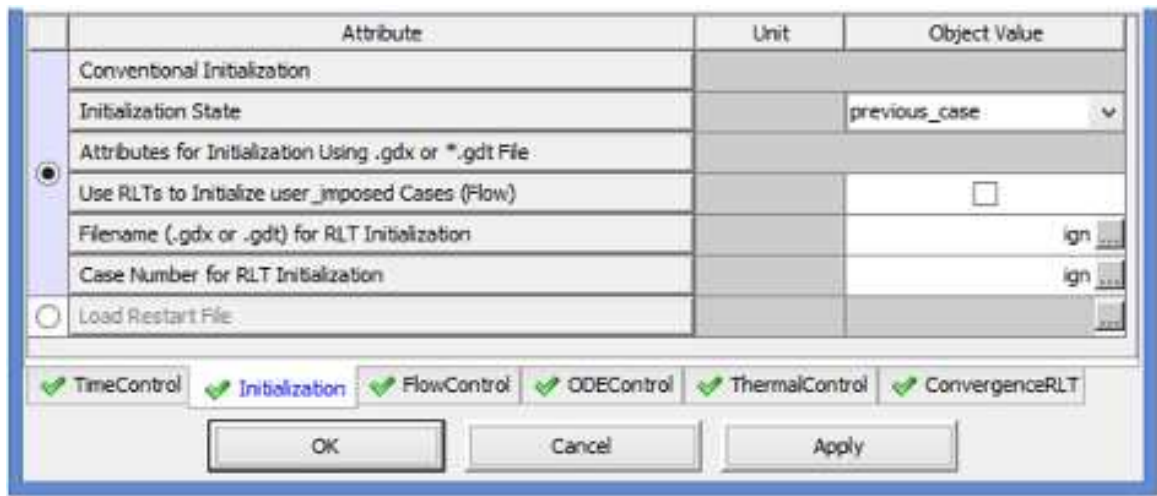

Figure 2; Initialization folder 


\section{ii. Case setup}

\section{Procedure:}

Go to the Run menu and select Case Setup of 3000 RPM. For the Case Label type 'Speed = [RPM]'

For the parameter RPM, type 'Engine Speed' for the Label and 3000 for the Case 1 value.

The text for the Case Label should now read 'Speed $=3000$. Make certain that the check box next to Case 1 is checked ON, indicating that Case 1 of the model will run when the simulation is run as shown in figure 3.

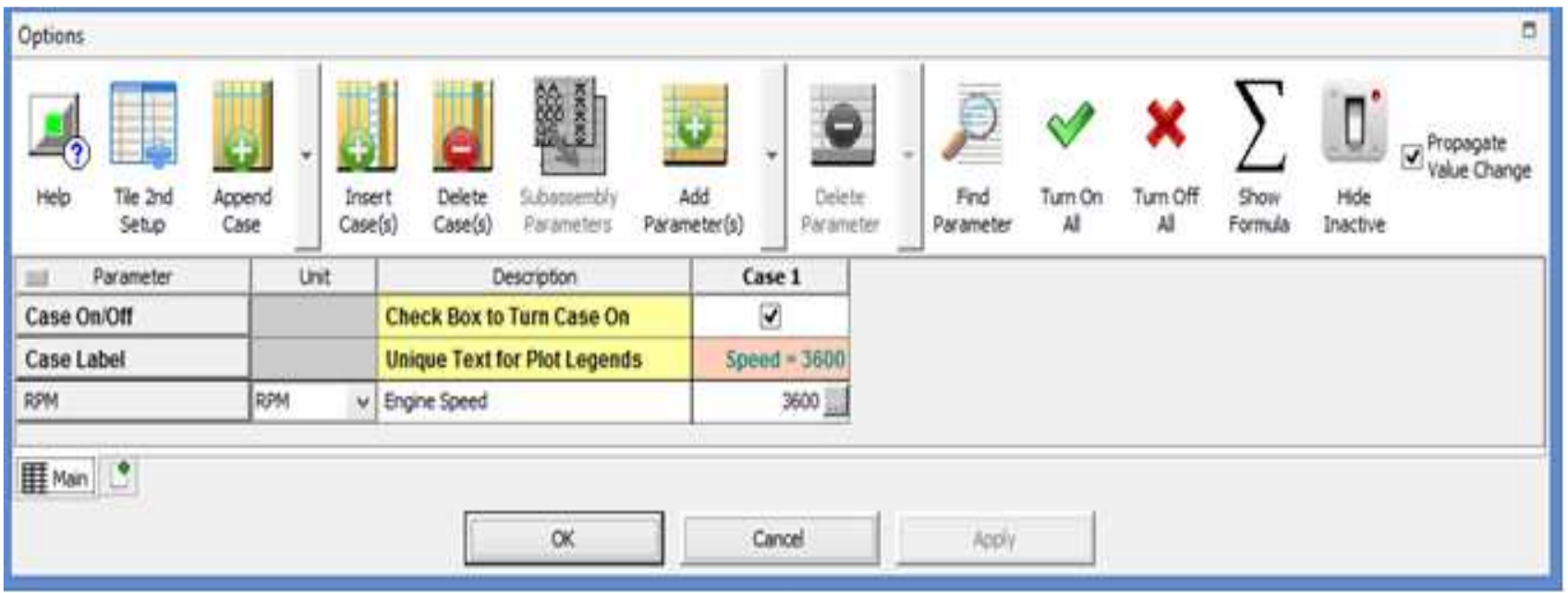

Figure 3; Case setup

\section{ii. Plot setup}

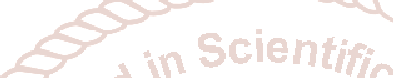

The final item before running the model is to request plots. Every applicable part on the project map has one or more folders for requesting what are referred to as instantaneous plots.

\section{Procedure:}

Double-click on the intake port part (intport-1), and go to the 'Flow' folder.

Select (check box on) Pressure (Static), Mass Flow Rate (at the Boundary), and Average Subvolume Velocity (centroid). For the intake and exhaust valves, in the 'Plots' folder, select Mass Flow Rate and Lift. For the cylinder, in the 'Plots: Flow' folder select Pressure, in the 'Plots: Thermal' folder select Temperature, and in the 'Plots: Combustion' folder select Burned Fuel Fraction and Apparent Heat Release Fraction.

All plot selections that have been made in the model can be viewed in one place by going toRun $>$ Plot Setup. Plot Setup allows the user to change details about each plot. The Plot Setup window should look similar to the figure 4 below.

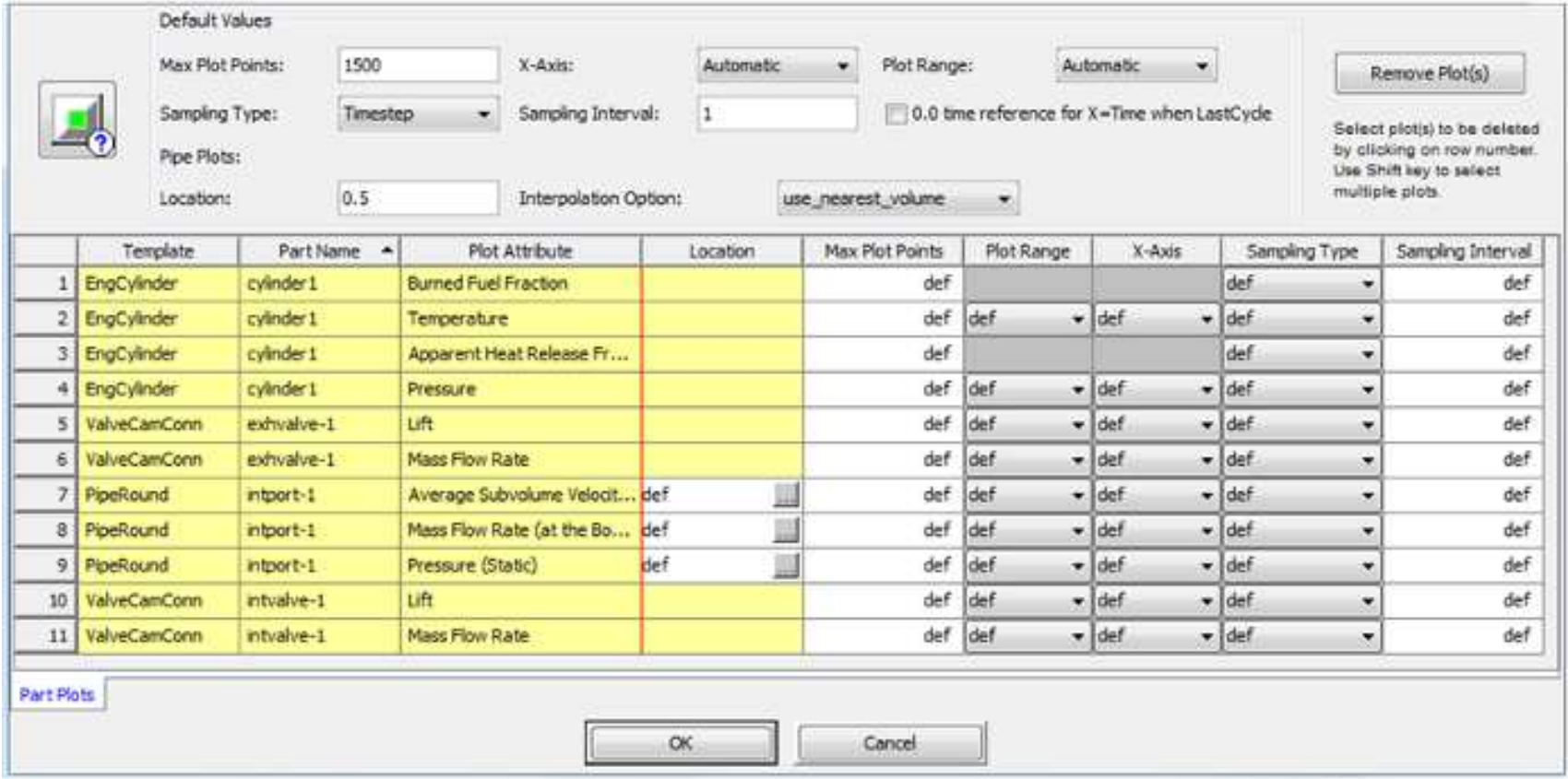

Figure 4; plot setup 


\section{RESULTS AND DISCUSSION}

Figure 1 shows the brake mean pressure with respect to the varied speed in the simulation model. From the result it was observed that the brake mean effective pressure is maximum and minimum at Case 4 and Case 1 respectively. This indicates that the brake mean pressure is peak value found to be 16.42 bar at Case 4 as the engine speed decreases hence brake power is maximum pressure is at case 4 when the engine speed is $1200 \mathrm{rpm}$.

Figure 2 shows the brake power with respect to the varied speed in the simulation model. It was observed that the brake power is declining from Case 1 which is maximum speed (3000 rpm) to Case 5 (600 rpm). This indicates that the power at the wheel decreases as the speed decreases.

Figure 3 shows Net Indicated Mean Effective Pressure with respect to the varied speed. The maximum Net IMEP, 18.5 bar is observed at Case $3(1800 \mathrm{rpm})$ and started declining after Case 3. In Figure 4 the maximum brake Torque, $102.75 \mathrm{~N}-\mathrm{m}$ is reached at $1200 \mathrm{rpm}$ and start declining as the speed reduces.

Figures 5 and 7 show that the Brake Specific Fuel Consumption, BSFC and Brake Specific $\mathrm{CO}_{2}$ are maximum at Case $1(3600 \mathrm{rpm})$ and decline as speed reduce. These show that more fuel is consumed at high speed.

Figures 6, 8 and 9 show that the Brake Specific CO, CO concentration and $\mathrm{CO}_{2}$ concentration are increasing as the speed reduces with values $0.01052 \mathrm{gkW}-\mathrm{h}, 1.87532 \mathrm{ppm}$ and $89000 \mathrm{ppm}$ at $3000 \mathrm{rpm}$ (Case 1), $0.01225 \mathrm{gkW}-\mathrm{h}, 2.62502$ ppm and $98900 \mathrm{ppm}$ at $600 \mathrm{rpm}$ (Case 5) respectively.

\section{CONCLUSION}

Biodiesel production is a modern and technological area for researchers due to constant increase in the prices of petroleum diesel and environmental advantages. Biodiesel from Neem oil was produced by alkali catalysed transesterification process, fuel simulated in a model of two cylinder compression ignition engine. Biodiesel fuel and pure diesel fuel performance characteristics and engine-out emissions in a model of direct injection compression ignition engines. The simulation model developed successfully captures the two cylinder compression ignition engine operating characteristics. The engine performance studies were conducted with a model of 2-cylinder CI engine using

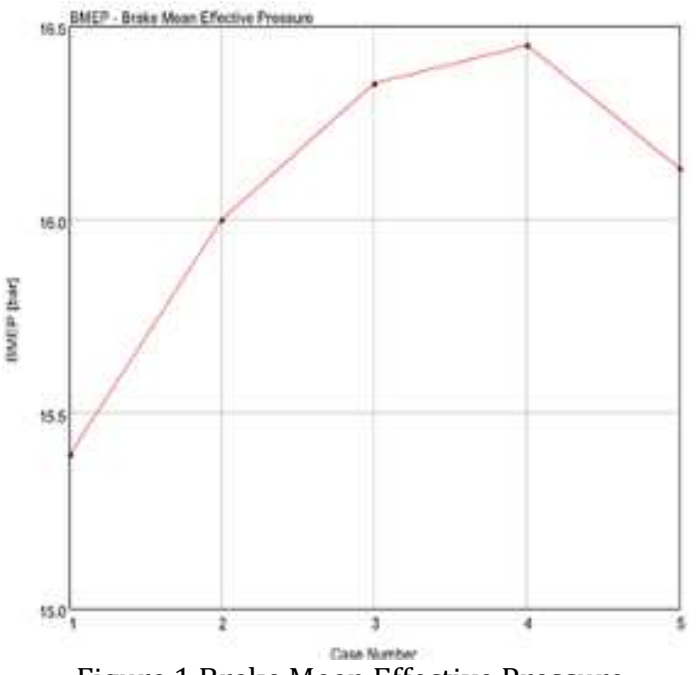

Figure 1 Brake Mean Effective Pressure
GT-Power suite package. The biodiesel has good lubricity as which is greater than petro-diesel when used in diesel engine. Results were validated for brake mean effective pressure, brake power, brake torque, Net mean effective pressure which were improved and low emission of $\mathrm{CO}$ and $\mathrm{CO} 2$. The biodiesel has good performance to replace fossil fuel and more environmentally friendly.

\section{REFERENCES}

[1] Aransiola, E. F., Ojumu, T. V., Oyekola, 0. 0., \& Ikhuomoregbe, D. I. O. (2012). A Study of Biodiesel Production from Non-Edible Oil Seeds: A Comparative Study. The Open Conference Proceedings Journal, 3, 18-22.

[2] Aransiola, E. F, Ojumu, T. V, Oyekola, O. O and Ikhuomoregbe, D. I. O. (2012). A Study of Biodiesel Production from Non-Edible Oil Seeds: A Comparative Study. The Open Conference Proceedings Journal, (Suppl 2-M1) 1-5.

[3] P. Tamil Porai, N. Nagarajan, (2013). Evaluation of performance and emission of Neem Oil Methyl Esther in a DI Diesel Engine.

[4] Aransiola, E. F., et al., Production of biodiesel by transesterification of refined soybean oil, Int. J. Biol. Chem. Sci., 4, No 2, 391-399 (2010).

[5] D. Y. Dasin, Yahuza I., Abdulsalam Y. A. and Gayang B. P. (2017), The Production And Investigation of The Physico - Chemical Properties of Biodiesel Produced From Neem (Azadiracta Indica) Seeds As Alternative Fuel In Compression Ignition Engines. Journal of Multidisciplinary Engineering Science and Technology, (JMEST) ISSN: 2458-9403 Vol. 4 Issue 9.

[6] Radha K. V. and Manikandan G. (2011) Novel production of biofuels from neem oil. In: World renewable energy congress, Sweden, 8-13 May 2011, pp.471-478.

[7] I. Yahuza, S. S. Farinwata, H. Dandakouta, D. Y. Dasin (2018), Production and Characterization of Biodiesel-Ethanol-Diesel Blend as Fuel in CompressionIgnition Engine. International Journal of Scientific Research in Science, Engineering and Technology (IJSRSET), Volume 4 Issue 1, Pp. 1415 - 1424.

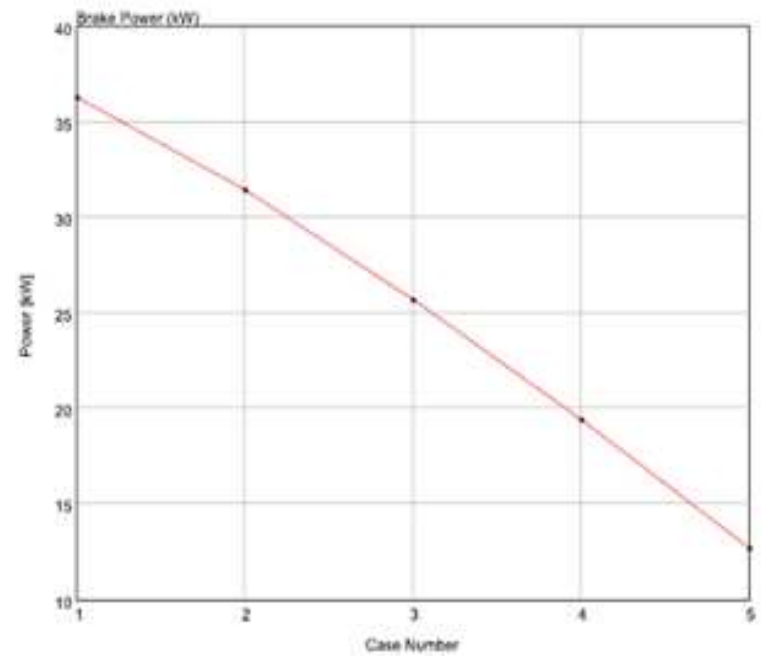

Figure 2 Brake Power 
International Journal of Trend in Scientific Research and Development (IJTSRD) @ www.ijtsrd.com eISSN: 2456-6470

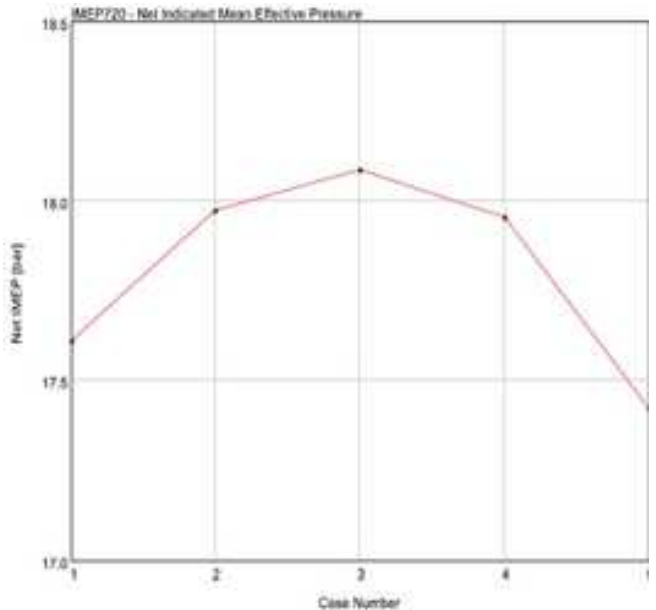

Figure3 Net Indicated Mean Effective Pressures

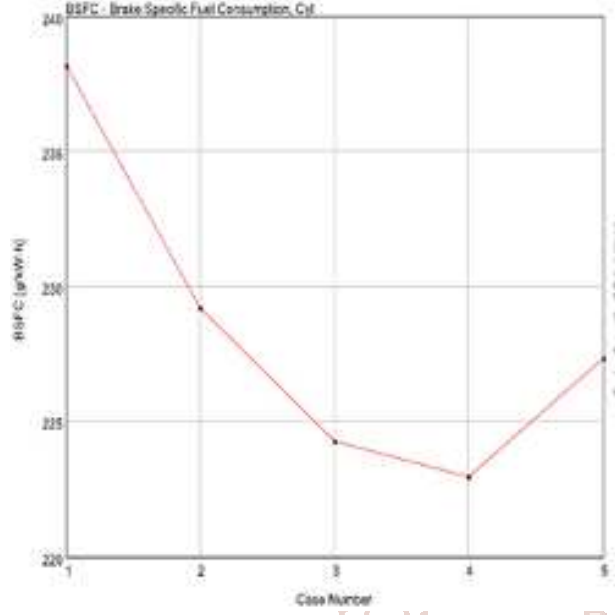

Figure5 Brake Specific Fuel Consumption

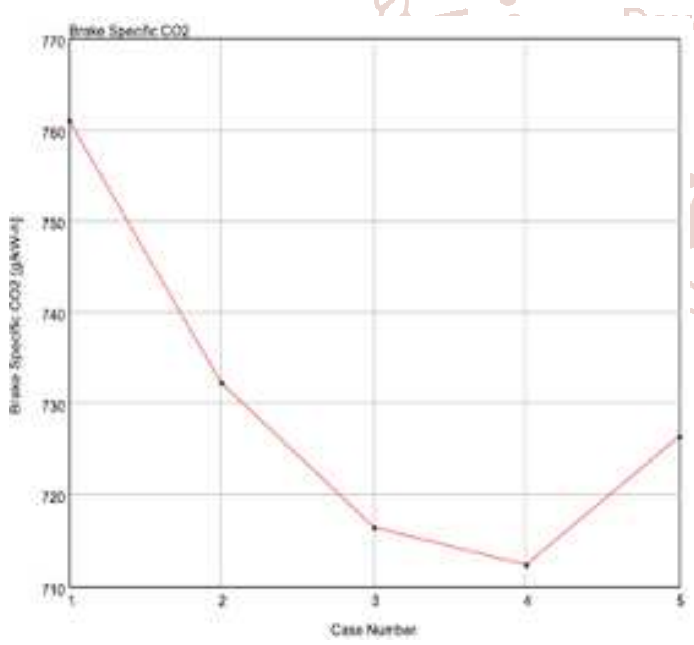

Figure7 Brake Specific CO2

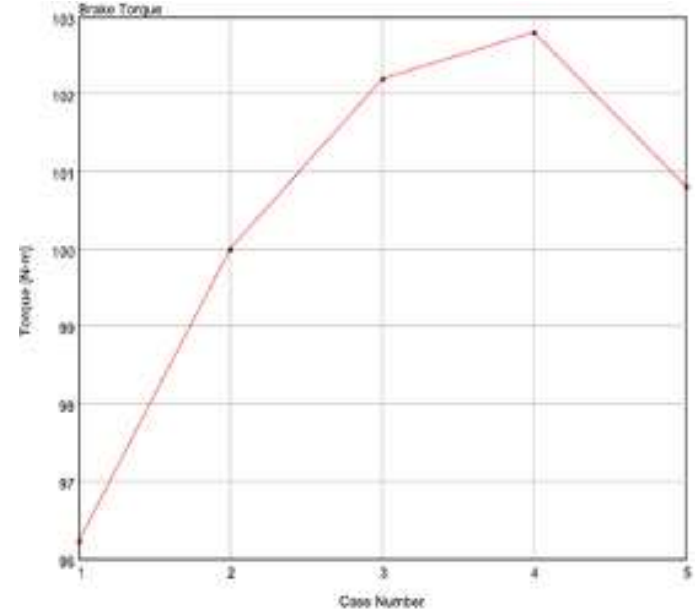

Figure4 Brake Torque

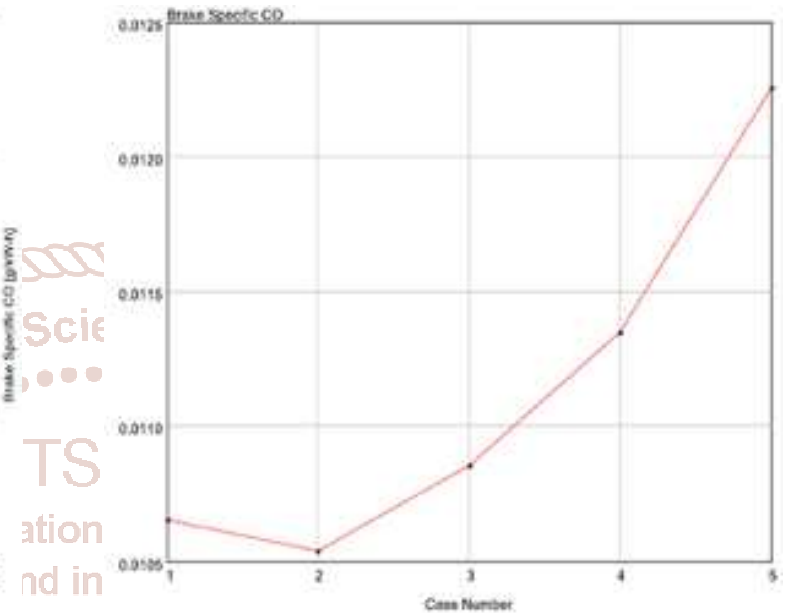

Figure6 Brake Specific CO

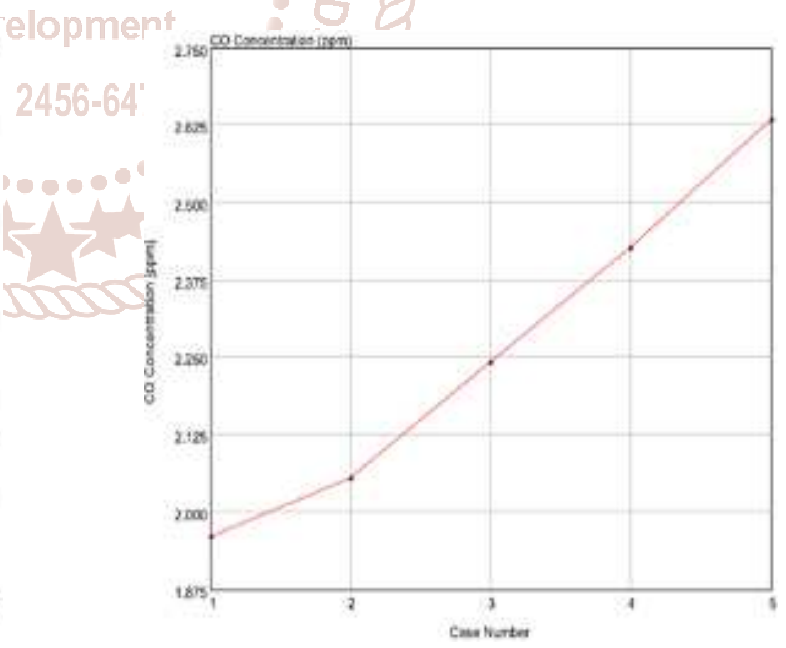

Figure8 C0 Concentration

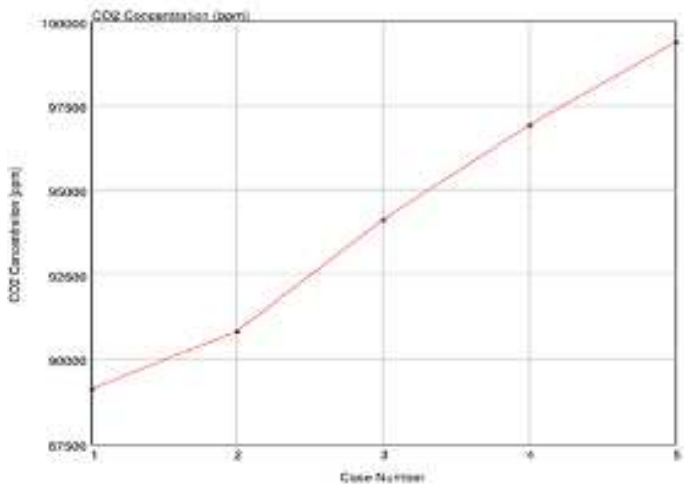

Figure 9 CO2 Concentration 